\title{
The Southeasterly Gale in Tianshan Grand Canyon in Xinjiang, China: A Case Study
}

\author{
Jinfeng DING \\ College of Meteorology and Oceanography, National University of Defense, Technology, China
}

Yangquan CHEN

Civil Aviation Air Traffic Control Bureau of Xinjiang Meteorological Center, China

Yuan WANG, and Xin XU

School of Atmospheric Sciences, and Key Laboratory of Mesoscale Severe, Weather of Ministry of Education, Nanjing University, China

(Manuscript received 22 February 2018, in final form 23 September 2018)

\begin{abstract}
The southeasterly gale in Xinjiang, China is a severe local weather phenomenon that is occasionally observed near the northwest opening of the Tianshan Grand Canyon. On 8 June 2013, a strong southeasterly gale attacked Urumchi with an average ground wind velocity of $15 \mathrm{~m} \mathrm{~s}^{-1}$ and wind gusts that reached $30 \mathrm{~m} \mathrm{~s}^{-1}$. The gale lasted for over $24 \mathrm{~h}$, making it the strongest wind in the last 20 years. Through observations and numerical simulation, this study describes the southeasterly gale's formation. The large-scale, topographic forcing from the Tianshan Mountains led to an intensification of the pressure gradient across the Tianshan Grand Canyon, creating a favorable gale condition. When air currents traveled through the canyon, establishing a critical layer with zero-wind velocity, the orographic forcing activated a non-linear process. The air current sank on the canyon's northwest opening due to unstable stratification which in turn strengthened the gale.
\end{abstract}

Keywords numerical simulation; severe weather; gale event

Citation Ding., J.,Y. Chen, Y. Wang, and X. Xu, 2019: The southeasterly gale in Tianshan Grand Canyon in Xinjiang, China: A case study. J. Meteor. Soc. Japan, 97, 55-67, doi:10.2151/jmsj.2019-002.

\section{Introduction}

China's Xinjiang region has extremely complex terrain. Figure 1 reveals the topography of the Xinjiang region and the Tianshan Grand Canyon. As

Corresponding author: Xin Xu, School of Atmospheric Sciences, and Key Laboratory of Mesoscale Severe Weather of Ministry of Education, Nanjing University, Jiangsu 210023, China

E-mail: xinxu@nju.edu.cn

J-stage Advance Published Date: 5 October 2018 shown, the Tianshan Mountains lie across central Xinjiang, dividing the entire region into two parts: Junggar Basin in the North and the Tarim and the Turpan Basins in the South. The Tianshan Grand Canyon is situated in the central Tianshan Mountains with a southeast-northwest orientation. The southeast opening is adjacent to Turpan Basin, and the northwest opening joins Junggar Basin. The city of Urumchi is located at the canyon's northwest opening, adjacent to the Junggar Basin's southern rim. A southeasterly gale describes a weather phenomenon with severe winds 
occurring near the canyon's northwest opening. The gale occurs unpredictably, with a region of rather high wind speed emerging from the center of the canyon and moving downstream through the northwest opening. When it happens, the city of Urumchi is typically characterized by a strong wind of up to $12 \mathrm{~m} \mathrm{~s}^{-1}$, affecting construction projects, traffic, agricultural production, and residents' daily routines.

Since the 1950s, when Urumchi began experiencing heavy urban development, residents have become increasingly concerned about gales. Using statistical analyses, local meteorologists have determined that gales occur most frequently in the spring and autumn, and they rarely occur in the summer. This gale lasts for at least two hours and sometimes as long as several days. When a southeasterly gale occurs, Urumchi is typically sunny but with increased temperature and reduced barometric pressure and humidity. The gale is normally generated when high pressure is distributed in the southeast of the Tianshan Grand Canyon along with low pressure in the northwest. Usually, when the sea-level pressure difference between the Turpan Basin and Urumchi reaches $5 \mathrm{hPa}$, the southeasterly gale occurs.

In the past few decades, gales occurring over complex terrain have gradually captured the public's attention. These events involve both downslope windstorms on the lee sides of mountains and gap winds. Other global locations with downslope windstorms include the Rocky Mountains (Klemp and Lilly 1975) and the Cascade Range (Colle and Mass 1998), both in the United States, as well as Mount Nagi (Fudeyasu et al. 2008) in Japan. Gap winds occur in places such as the Shelikof Strait (Colman and Dierking 1992) in Alaska and the Strait of Juan de Fuca (Overland and Walter 1981) separating the United States and Canada. Based on observations, theoretical analyses, and numerical simulations, meteorologists have determined that both types of gales are generated by topographically-activated atmospheric gravity waves. Clark and Peltier (1977 and 1984) explained the downslope windstorm phenomenon according to the resonance mechanism. They suggested that breaking large-amplitude gravity waves is usually accompanied by turbulent mixing and a local wind field reversal, forming a critical layer (i.e., zero-wind velocity layer) that can reflect upward-propagating gravity waves back to the surface. As a result, the surface wind speed on the terrain's lee slope can be significantly enhanced. Durran (1986) had a different interpretation, suggesting that the subcritical flow from upstream will transform into a supercritical flow when it travels over the ridge, converting potential energy to kinetic, with a subsequent downslope windstorm on the lee side. This type of process is similar to the hydraulic jump phenomenon in a homogeneous shallow water model. Despite some differences, both theories agree that a downslope windstorm is largely generated from breaking gravity waves since the resulting turbulent mixing can reflect gravity waves and speed up the surface wind velocity.

Overland and Walter (1981) defined gap winds as airflow in a sea-level channel that accelerates under the influence of a pressure gradient force parallel to the channel's axis. The local winds are in approximately ageostrophic equilibrium between the inertial and pressure gradient forces. Zängl (2002) applied linear theory and conducted a non-linear numerical simulation on these weather phenomena. First, linear theory states gap wind development is related to both low-level confluence at the gap and three-dimensional gravity waves; however, the simulation results showed that the low-level pressure difference across a mountain ridge is the largest contributor to gap wind generation. Gaberšek and Durran (2004) also conducted an idealized simulation to reveal an air current passing over an isolated flat-top ridge cut by a straight narrow gap. Their study indicated that the non-linear motion of gravity waves introduced a large downward mass and momentum toward the exit area of the gap, thus producing gales.

On 8 June 2013, a strong southeasterly gale attacked Urumchi with a sustained wind speed of up to $15 \mathrm{~m} \mathrm{~s}^{-1}$ and gusts reaching $30 \mathrm{~m} \mathrm{~s}^{-1}$. It lasted for more than $24 \mathrm{~h}$, the strongest gale in 20 years. This study simulates the incident using a weather research and forecasting (WRF) model to identify the gale's causes and structure. Section 2 introduces the data and model configuration for this study. Section 3 gives the incident's synoptic meteorological background and describes the gale's structural characteristics. Section 4 analyzes the causes of the southeasterly gale, and Section 5 presents a conclusion.

\section{Data and model configuration}

\subsection{Data}

Observations of surface temperature and sea-level pressure are derived from two automatic weather stations (AWS), indicated by circles in Fig. $1 \mathrm{~b}$ of the Urumchi $\left(43.78^{\circ} \mathrm{N}, 87.62^{\circ} \mathrm{E}\right)$ and Turpan $\left(42.93^{\circ} \mathrm{N}\right.$, $\left.89.20^{\circ} \mathrm{E}\right)$ stations. These data facilitate real-time reports from the Argos satellite communication system. We also used data from the aircraft meteorological data relay (AMDAR) system, installed on a com- 


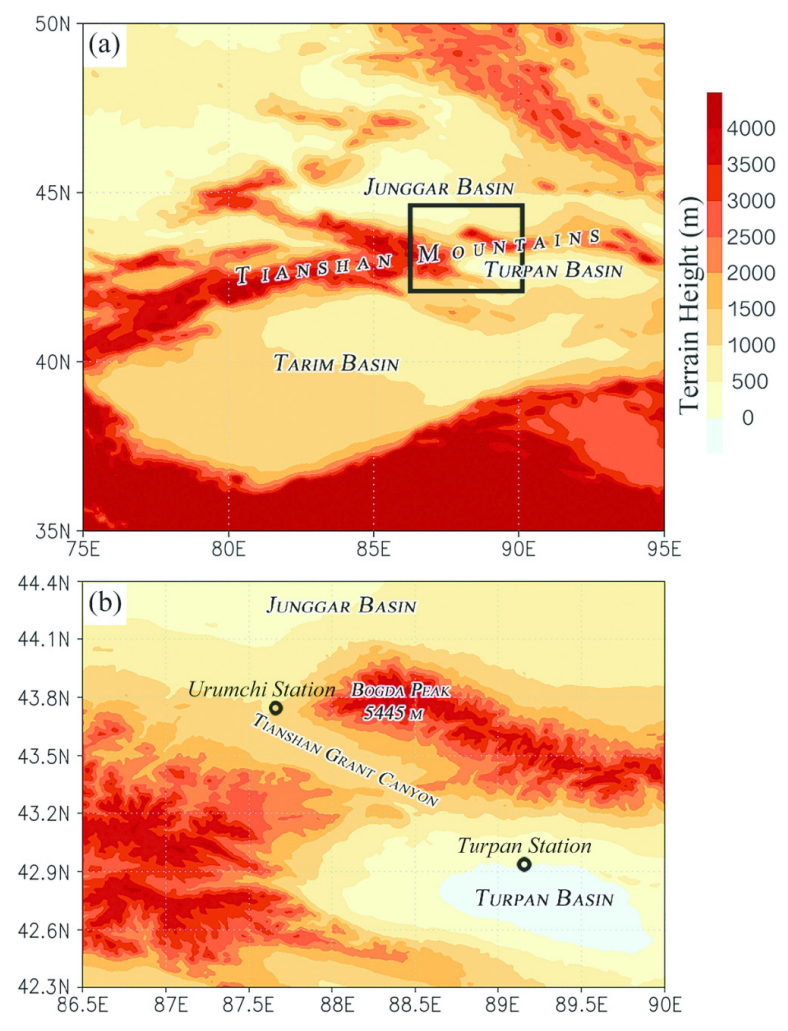

Fig. 1. (a) A topographic map of the Xinjiang region. (b) An enlarged map of the Tianshan Grand Canyon indicated by the black box in (a).

mercial aircraft that departed from and landed at the Urumchi airport $\left(43.91^{\circ} \mathrm{N}, 87.47^{\circ} \mathrm{E}\right)$. These were used as temperature profile observations. For southeasterly gale wind speed, we used observational data from the meteorological terminal aviation routine weather report (METAR), acquired from a station installed 10 $\mathrm{m}$ off the ground at the Urumchi airport, which has an observation frequency of $30 \mathrm{~s}$.

The initial field of meteorological elements, as well as the lateral-boundary conditions required by numerical simulation, derive from the $0.5^{\circ}$ analysis provided by the historical unidata internet data distribution (IDD) gridded model data (National Centers for Environmental Prediction (NCEP) et al. 2003). In addition, the $1^{\circ}$ final operational global analysis data (FNL), derived from the global assimilation system (GDAS), is used as a practical reference for large-scale synoptic situations (National Centers for Environmental Prediction et al. 2000).

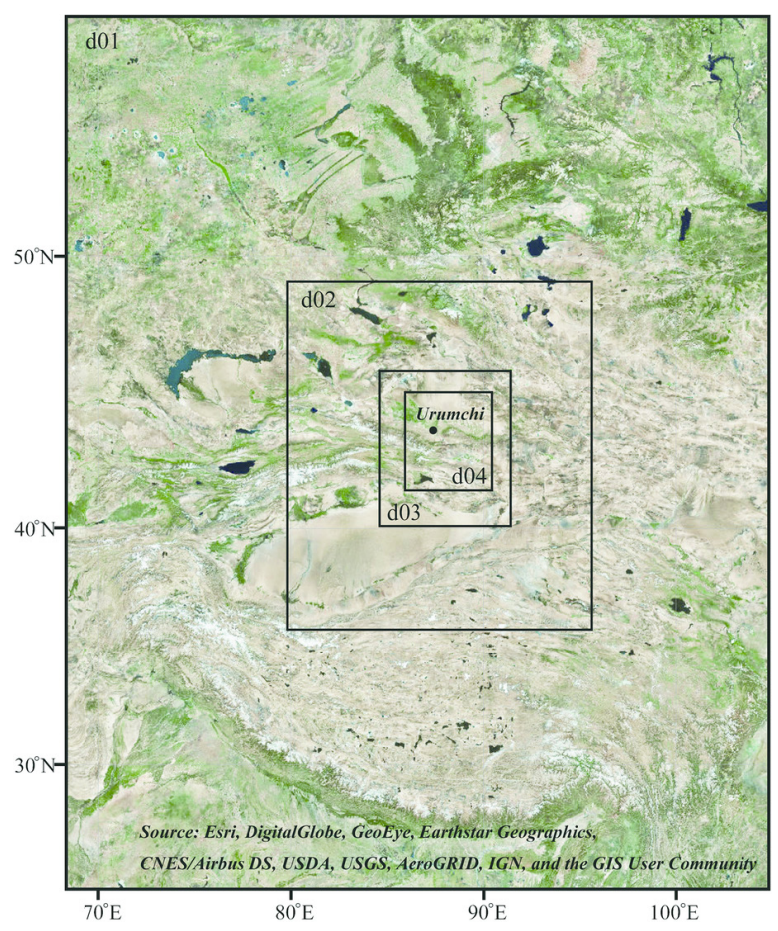

Fig. 2. The WRF model's domain configuration.

\subsection{Model configuration}

The WRF model used in this study, which is fully compressible and non-hydrostatic, was developed by the NCEP and National Center for Atmospheric Research (NCAR) (Skamarock et al. 2008). The model domain is quadruple-nested with horizontal grid resolutions of $27,9,3$, and $1 \mathrm{~km}$, respectively, and grid numbers of $180 \times 170,145 \times 133,211 \times 193$, and $346 \times 337$, respectively. Figure 2 shows the domain configuration. The geographical base map is provided by world imagery data. Fifty layers are used in the vertical direction, with the model top located at $50 \mathrm{hPa}$. Furthermore, the radiative transfer for an inhomogeneous atmospheres scheme (RRTM, Mlawer 1997) is used as the long-wave-radiation scheme. For short-wave radiation, the Dudhia short-wave scheme (Dudhia 1989) is applied. The fifth generation of the Penn State/NCAR Mesoscale Model (MM5) similarity scheme (Paulson 1970) is adopted for the surfacelayer option. The land surface option uses the unified Noah land-surface model (Tewari et al. 2004), and the Mellor-Yamada-Janjić (MYJ) scheme (Janjić 1994) is selected for the planetary boundary layer. The precipitation scheme is not used for the fourth domain. The model started at 0000 UTC 08 June 2013 (abbreviated 
as 0000 UTC 08 hereafter), but because the initial field of meteorological elements could not satisfy the kinetic equations of the model, a 6-h spin-up was required. The output started at 0600 UTC 08 and ran for $30 \mathrm{~h}$. The results presented as follows were obtained from the $1-\mathrm{km}$ resolution simulation results.
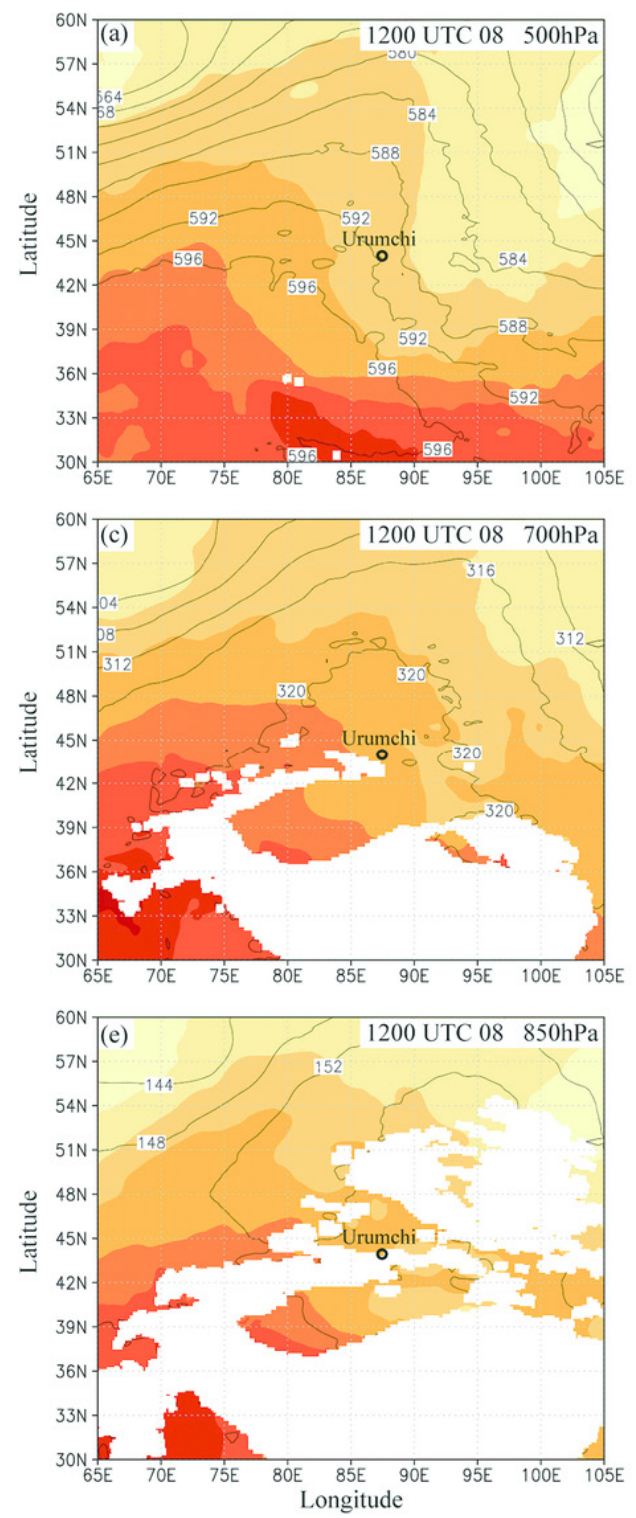

\section{Overview of the gale event}

3.1 Synoptic situation analyses and observed results The synoptic situation analyses shown in Fig. 3 were sourced from FNL data. We demonstrated that at 1200 UTC 08 , the high-pressure ridge at $500 \mathrm{hPa}$ was located west of Urumchi and kept moving east over the next few days, during which it always stayed ahead of the thermal ridge. With the eastward motion
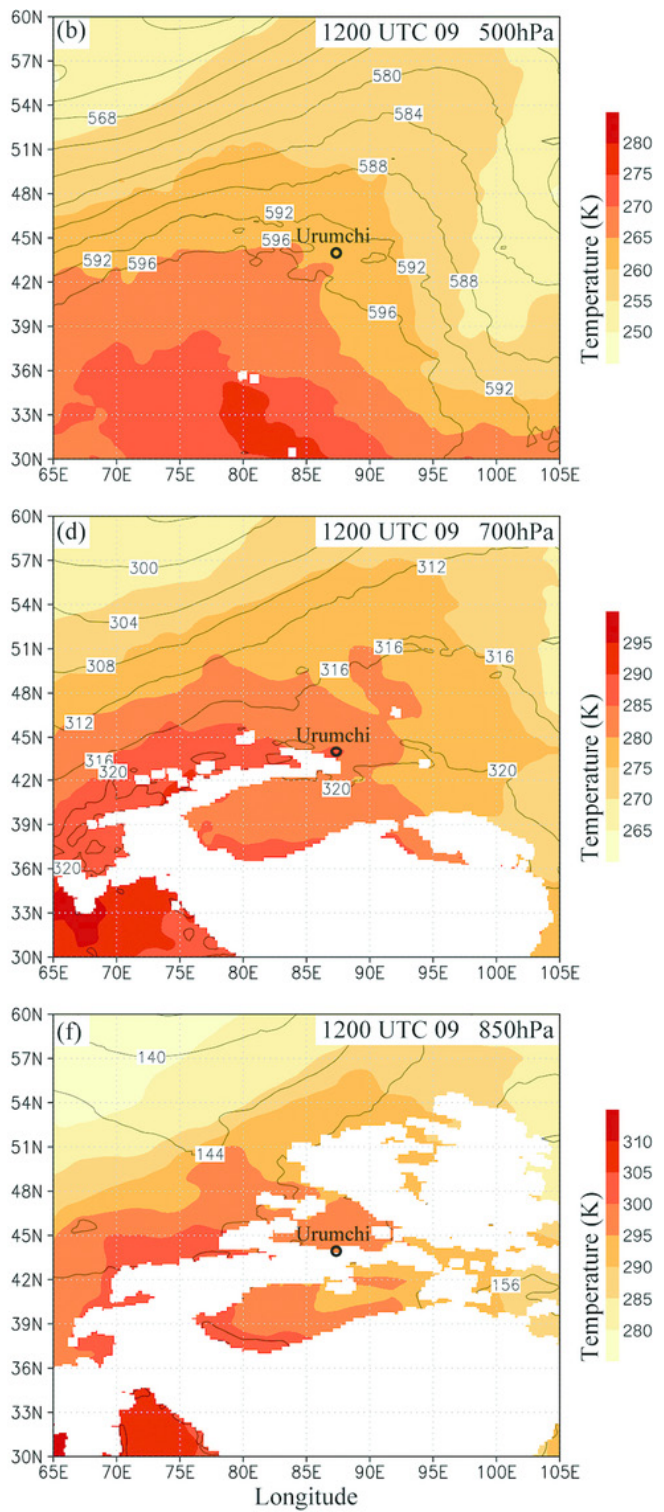

Fig. 3. Synoptic conditions at (a), (b) $500 \mathrm{hPa}$, (c), (d) $700 \mathrm{hPa}$, and (e), (f) $850 \mathrm{hPa}$. (a), (c), and (e) are at 1200 UTC 08 June 2013, and (b), (d), and (f) are at 1200 UTC 09 June 2013. Black isolines indicate the geopotential height at 40 geopotential meter intervals, and the isoline values were obtained by dividing geopotential heights by 10 . The shaded areas represent temperature fields. 
of the large-scale warm ridge, the Tianshan region, lower in the troposphere, began to warm up. In addition, the temperature near the north of the Tianshan Mountains, at $700 \mathrm{hPa}$ and $850 \mathrm{hPa}$, increased faster than near the south. Figures $4 \mathrm{a}$ and $4 \mathrm{~b}$ show surface temperature variations and sea-level pressure for the Urumchi and Turpan stations, respectively. These two AWS stations were on each side of the Tianshan Grand Canyon, with an observational time interval of $3 \mathrm{~h}$. For the daily mean temperature (the average of three hourly temperature measurements), the Urumchi station detected more significant growth than the Turpan station, which was consistent with the temperature variation trend at $850 \mathrm{hPa}$. Simultaneously, because of the quick surface temperature change, which is related to the fact that the area in question is a desert climate, diurnal variation of the sea-level pressure for the Turpan station took on a single-peak curve. At the Urumchi station, a continuous drop in sea-level pressure was observed, which was different from the norm. Thus, low and high pressure fields were respectively found in the northwest and southeast of the Tianshan Grand Canyon from 1600 UTC 08. The METAR simultaneously detected the emergence of a southeasterly wind, as shown in Figs. $4 \mathrm{c}$ and $4 \mathrm{~d}$.
The wind direction suddenly veered to $150^{\circ}$ at that time. Over the following hours, the southeasterly gale strengthened very quickly, and a wind speed greater than $15 \mathrm{~m} \mathrm{~s}^{-1}$ later occurred at 2100 UTC 08 . The model captured the pressure changes accurately as well as the gale's generation time, strength, and direction at both AWS stations.

\subsection{Structural characteristics of the southeasterly gale}

Figures 5-7 display the structural features of the southeasterly gale derived from the simulation. At 1300 UTC 08, as shown in Fig. 5, a southeast air current had already emerged in the lower atmosphere on both sides of the canyon. However, the air current on the southeast side continued to have difficulty crossing the canyon because of the high terrain in the southeast opening area (near $43.2^{\circ} \mathrm{N}, 88.4^{\circ} \mathrm{E}$ ) which blocked the still-weak southeast air current.

The gale's structural features at 1600 UTC 08 are shown in Fig. 6. At $850 \mathrm{hPa}$, the geopotential height on the canyon's northwest side decreased noticeably, resulting in a $10 \mathrm{~m}$ difference in geopotential height across the canyon. The airflow on the southeast side could travel across the canyon and connect with the air
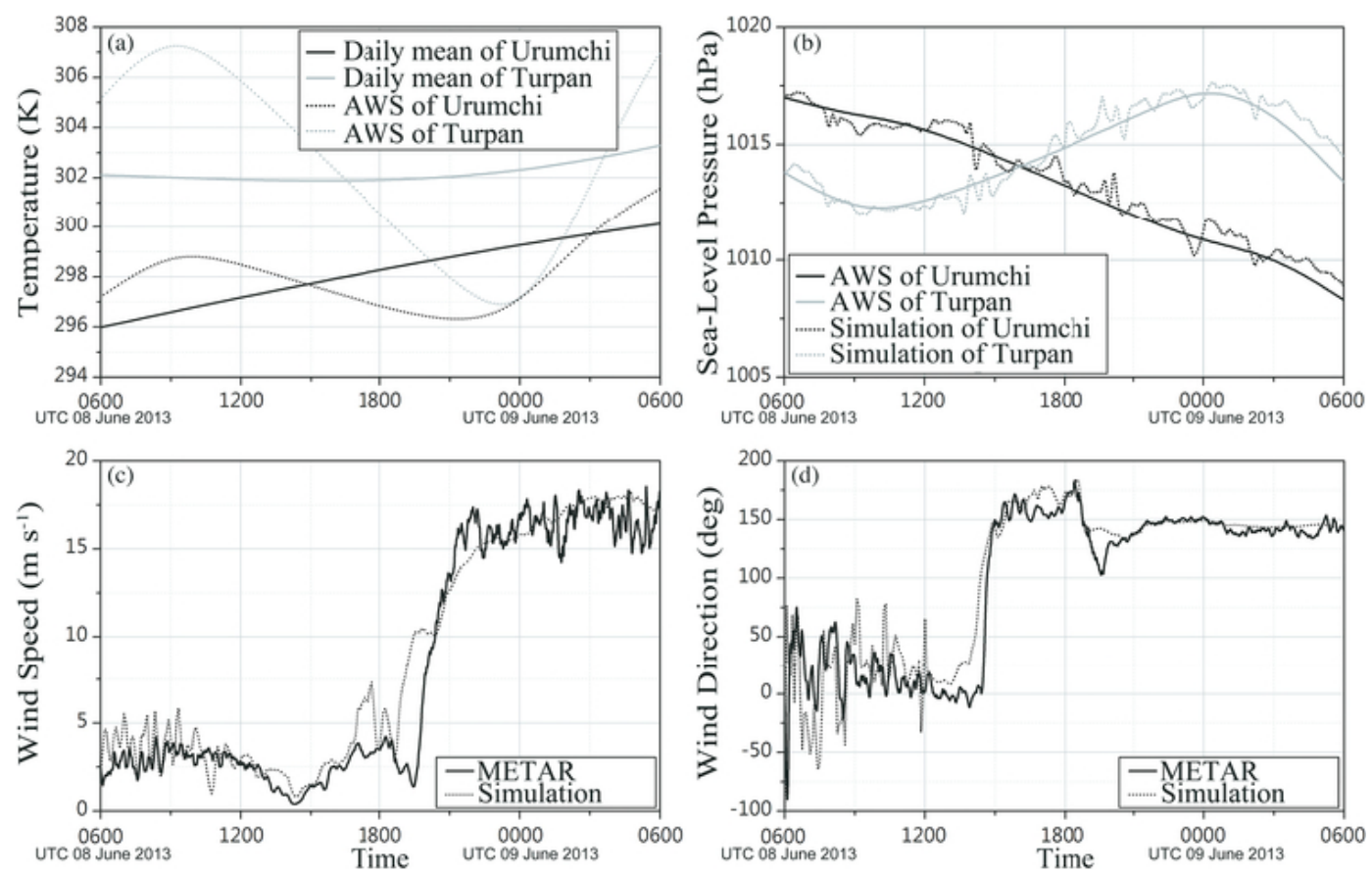

Fig. 4. (a) Temperature observations derived from 3-h interval AWS. The dotted lines represent measured observations, and solid lines represent the daily averages. (b) Sea-level pressure, (c) wind speed, and (d) wind direction observations derived from AWS and simulated results. 

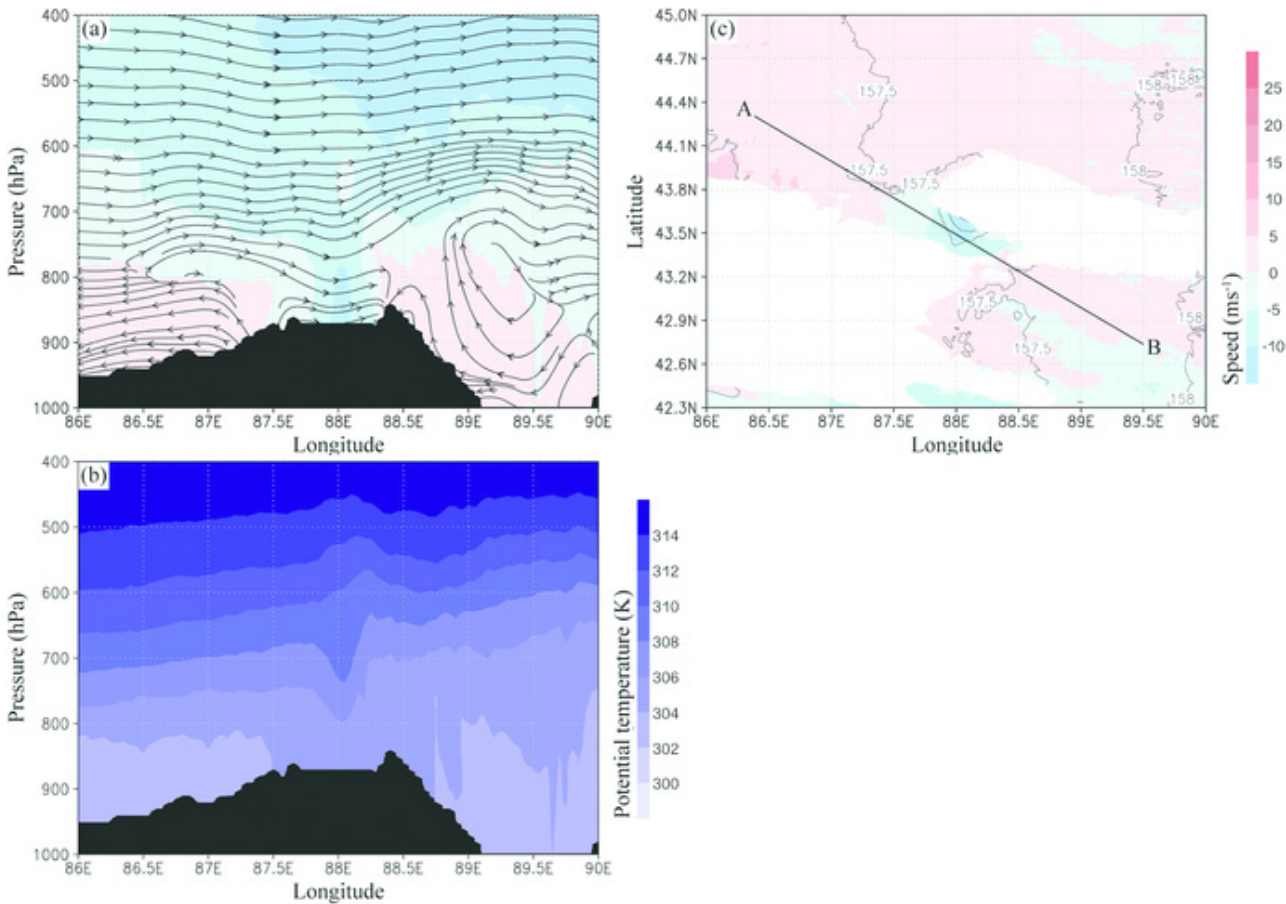

Fig. 5. Simulated results at 1300 UTC 08 June 2013: (a) The cross section along line AB in (c) of flow and horizontal wind speed (horizontal wind is projected onto the cross section, with a positive value indicating a northwestward wind), (b) cross section of potential temperature, (c) horizontal wind speed in the direction of line $\mathrm{AB}$ and geopotential height fields at $850 \mathrm{hPa}$. The black isolines indicate the geopotential height at 5 geopotential meter intervals, and the isoline values were obtained by dividing geopotential heights by 10 .
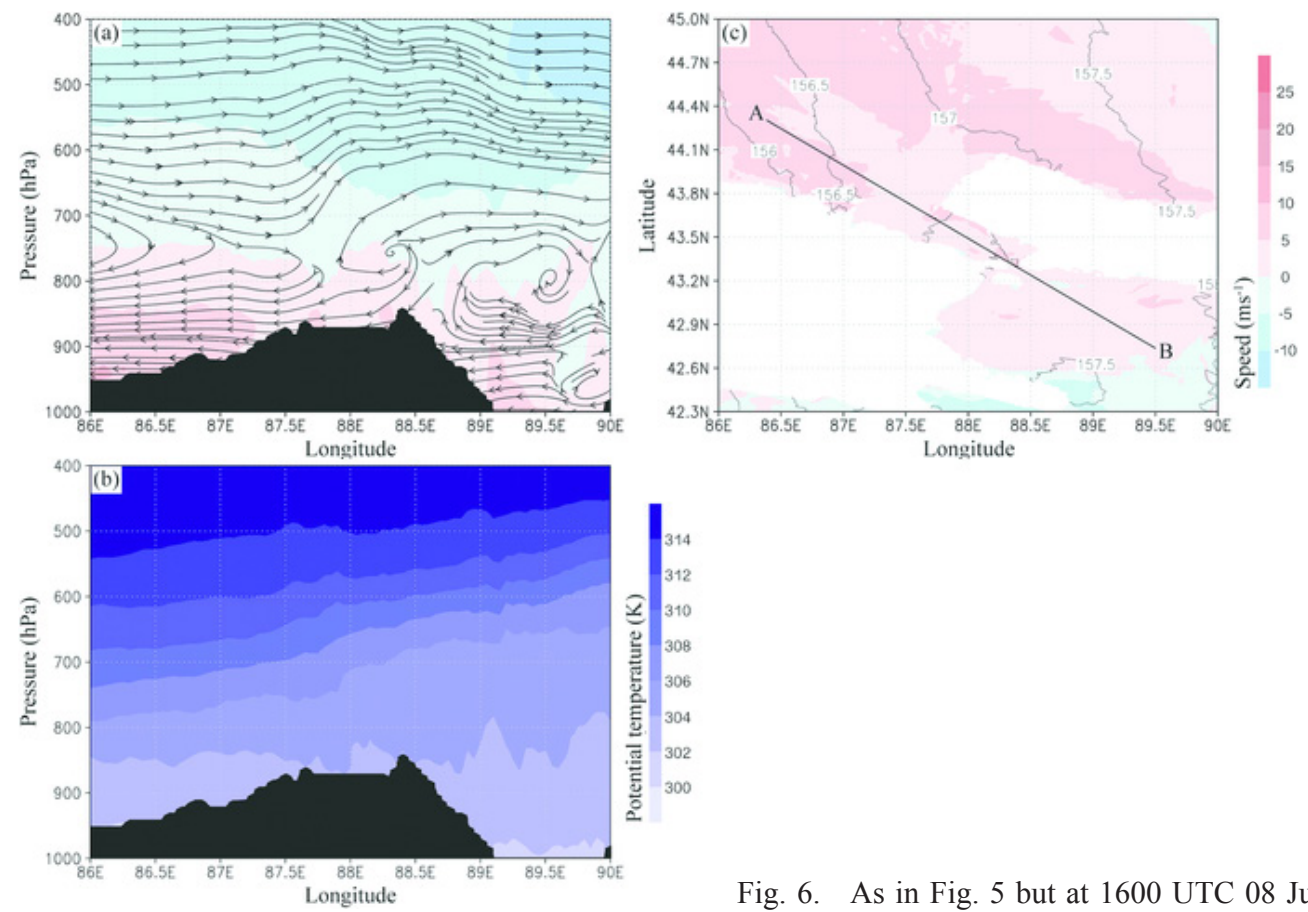

Fig. 6. As in Fig. 5 but at 1600 UTC 08 June 2013. 

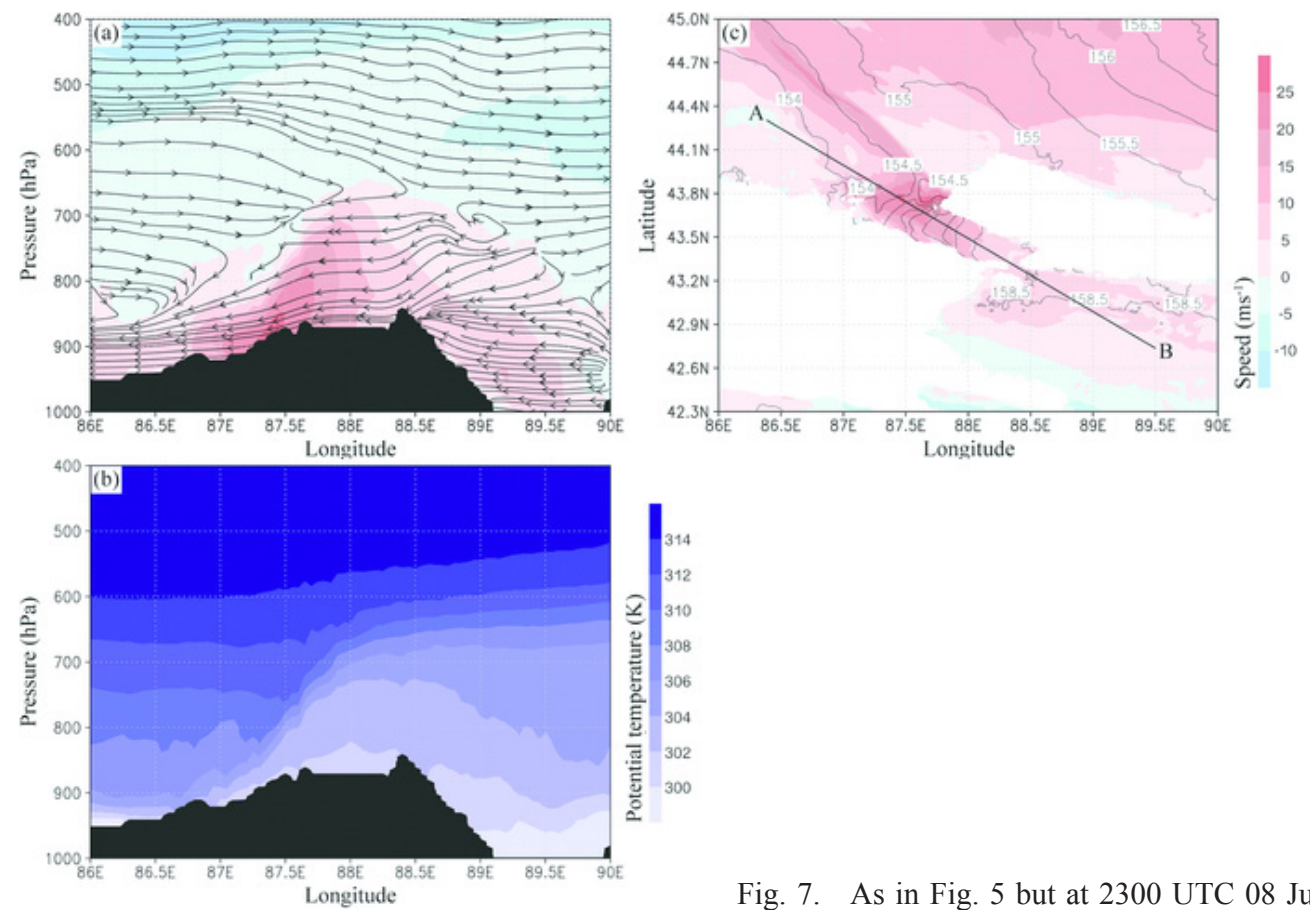

Fig. 7. As in Fig. 5 but at 2300 UTC 08 June 2013.

current on the northwest side in the lower atmosphere. As a result, a zero-wind layer was formed at a height between $700 \mathrm{hPa}$ and $800 \mathrm{hPa}$ above the canyon, which is called a critical layer (Booker and Bretherton 1967).

Later, at 2300 UTC 08 as shown in Fig. 7, the isentropes shifted downward to the northwest opening of the canyon, while the southeasterly gale structure was formed with a velocity exceeding $20 \mathrm{~m} \mathrm{~s}^{-1}$. This structure was similar to that derived from the idealized experiment, conducted by Gaberšek and Durran (2004), for the air current having a Froude number $(F r=U / N H)$ of approximate unity passing over an isolated flat-top ridge cut by a straight narrow gap.

\section{Causes of the southeasterly gale}

The last section described the southeasterly gale's synoptic situations and structural characteristics. It seems that the pressure gradient across the canyon is the critical factor contributing to gale generation. However, how it was formed must still be considered. In the meantime, we can determine why the wind speed increased so sharply as soon as the critical layer emerged.

\subsection{Diagnostic analysis of gale generation}

To determine the incident's causes, a control volume was placed at the canyon's northwest opening with the center at $\left(87.6^{\circ} \mathrm{E}, 43.6^{\circ} \mathrm{N}\right)$, as shown in Fig. 8 . The length of the control volume was $0.2^{\circ}$ projected onto the latitude, with a width of $0.1^{\circ}$ projected onto the longitude. The volume height was $2 \mathrm{~km}$ above sea level. In Fig. 5c, the $x$ axis is parallel to line AB. A balance equation of momentum was then used to diagnose the motion status of airflow passing the control volume. The equation in the $x$ direction can be written as:

$$
\begin{aligned}
& \iiint \frac{\partial(\rho u)}{\partial t} d x d y d z \\
& \quad=P_{x}+\left(F_{x}+F_{y}+F_{z}\right)+F_{\text {dissipation }},
\end{aligned}
$$

with $F_{x}=-\iiint\left(\frac{\partial(\rho u)}{\partial x} \cdot u\right) d x d y d z, F_{y}=-\iiint\left(\frac{\partial(\rho u)}{\partial y} \cdot v\right)$ $d x d y d z, \quad F_{z}=-\iiint\left(\frac{\partial(\rho u)}{\partial z} \cdot w\right) d x d y d z, \quad$ and $\quad P_{x}=$ $-\iiint\left(\frac{\partial p}{\partial x}\right) d x d y d z$. In addition, $u, v$, and $w$ are the velocity components along the $x, y$, and $z$ axes, respectively, and $F_{x}, F_{y}$, and $F_{z}$ are the stress forces on the control volumes imposed by the air current flowing into or out of the volume in the directions of $x, y$, and $z$, respectively. Thus, the momentum changes in the $x$ direction are generated by the joint effects of $F_{x}, F_{y}$, and $F_{z}$, the horizontal pressure gradient force $P_{x}$, and the dissipation force.

Figure 9a shows the resultant force variations of pressure gradient and stress forces, as well as the 


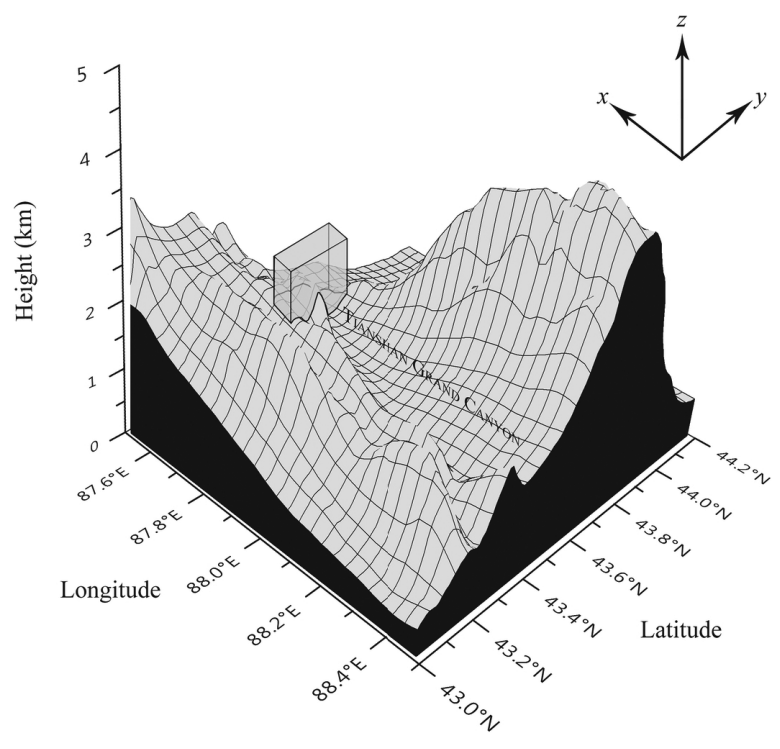

Fig. 8. The 3D terrain of the canyon's northwest opening. The box indicates the control volume used for diagnostic analysis with a length of $0.2^{\circ}$ projected onto the latitude, a width of $0.1^{\circ}$ projected onto the longitude, and a height of $2 \mathrm{~km}$ above sea level. The $x$ axis is parallel to line $\mathrm{AB}$ in Fig. 5c. momentum variation rate of the control volume. Figure $9 \mathrm{~b}$ shows the individual variations of $P_{x}, F_{x}$, and $F_{z}$ to evaluate their contributions quantitatively. Simultaneously, Figs. 9c and 9d show the variations of the mean horizontal wind speed in the $x$ direction and mean vertical speed of the control volume. Based on the mean horizontal wind speed in the $x$ direction, the entire gale generation process could be divided into three stages. The first stage was before 1600 UTC 08 . The pressure gradient force across the control volume increased, but remained negative, and the wind speed increased very slowly. The acceleration was mainly produced by momentum from the air upstream, indicated by the positive $F_{x}$ during this stage. In addition, the control volume momentum variation rate was basically the same as the sum of the pressure gradient and stress forces, indicating almost no dissipation effect in the control volume. The second stage was from 1600 UTC 08 to 2300 UTC 08, during which the southeasterly wind strength increased significantly; the primary cause was rapid growth of the pressure gradient force. In addition, vertical motion, indicated by the vertical speed (Fig. 9d), strengthened during this stage with turbulence dissipation. During the third stage, the southeasterly gale strength was retained. The pressure gradient force remained strong, and the vertical motion became even more significant. However, the negative $F_{x}$ balanced the momentum acquired from $P_{x}$ and $F_{z}$, indicating a strong momentum in the
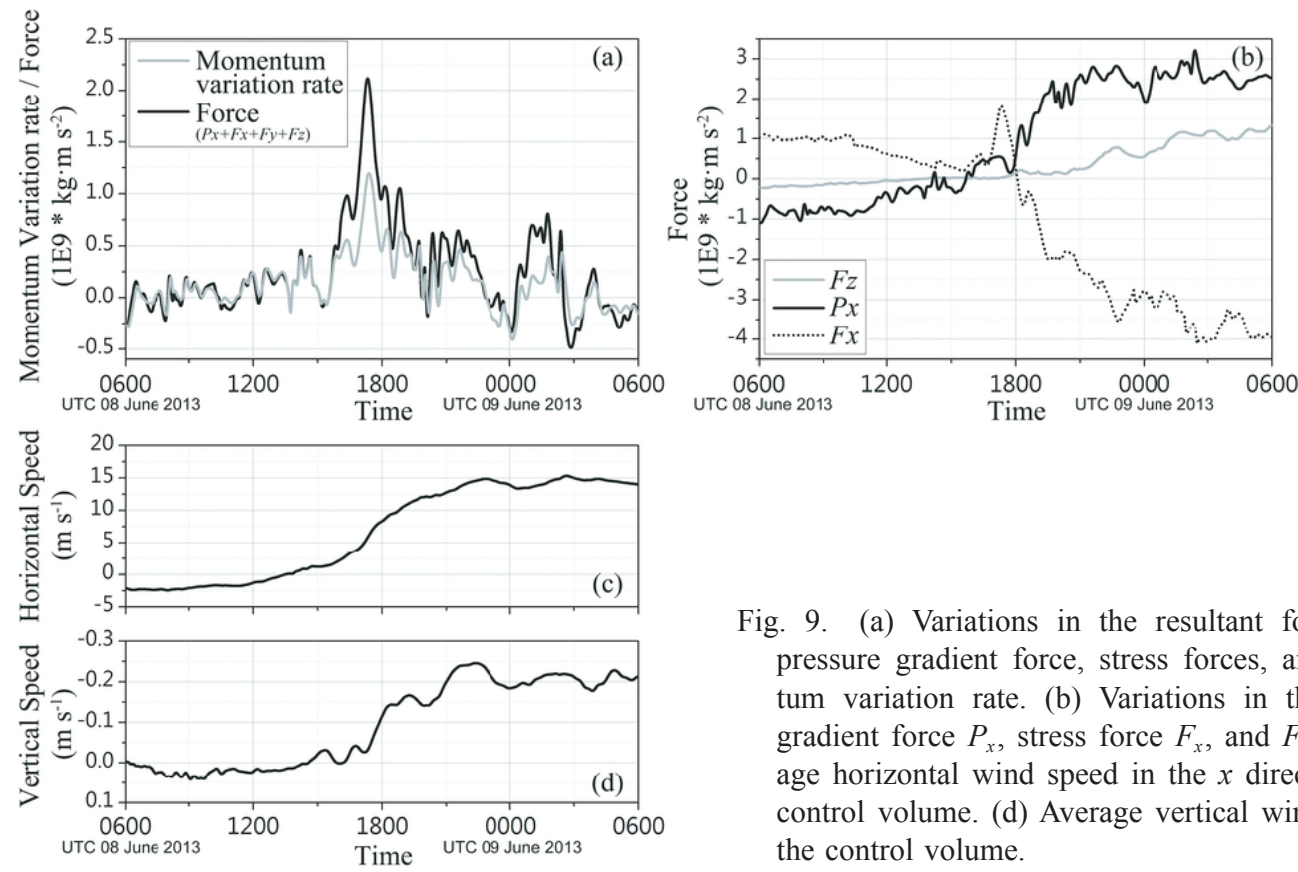

Fig. 9. (a) Variations in the resultant force of the pressure gradient force, stress forces, and momentum variation rate. (b) Variations in the pressure gradient force $P_{x}$, stress force $F_{x}$, and $F_{z}$. (c) Average horizontal wind speed in the $x$ direction of the control volume. (d) Average vertical wind speed of the control volume. 
downstream direction.

In general, the induced pressure gradient, along with sinking acceleration, were critical factors contributing to this gale event.

\subsection{Formation of the pressure gradient across the canyon}

The local sea-level pressure equals the weight per unit area of the air column from sea level to the top. When local warming occurs inside the air column, the air density diminishes as the air temperature rises. This may reduce the sea-level pressure. The AWS observations of the surface temperature, as shown in Fig. $4 \mathrm{a}$, revealed that, during gale generation, the temperature at Turpan remained basically unchanged, but it increased at Urumchi. Why did the air get warmer, especially before the gale was generated?

For the local change of temperature:

$$
\begin{aligned}
\partial T / \partial t= & -(u \partial T / \partial x+v \partial T / \partial y) \\
& +1 / C_{p} \cdot d Q / d t-w\left(\gamma_{d}-\gamma\right),
\end{aligned}
$$

where $\gamma_{d}$ and $\gamma$ denote the lapse rates of dry and real air temperature, respectively, $C_{p}$ represents the specific heat at a constant pressure, and $Q$ is the diabatic heating. The first term, on the right hand side (RHS) of (2), indicates the horizontal advection effect. Figures $10 \mathrm{a}$ and $10 \mathrm{~b}$ represent the temperature and wind field at $850 \mathrm{hPa}$ for $1300 \mathrm{UTC} 08$ and 1700 UTC 08, respectively. The high Tianshan Mountains blocked the relatively warm atmosphere's eastward motion, leaving the warm air west of the mountains. By integrating the first term on the RHS of (2) at 850 $\mathrm{hPa}$ from 1300 UTC 08 to 1700 UTC 08 using the simulated results, we identified an incredibly small average variation of $0.12^{\circ} \mathrm{C}$ over the area of $(44-$ $44.5^{\circ} \mathrm{N}, 84-87^{\circ} \mathrm{E}$ ), which proved that practically no eastward horizontal warm advection occurred on the north foot of the Tianshan Mountains. The second term on the RHS of (2) is diabatic. Because of radiative cooling at night, areas with higher temperatures, at $850 \mathrm{hPa}$ in the basin located on the south side of the mountains, gradually shrunk. By contrast, on the north foot of the mountains, regional temperatures visibly increased along the mountains. Therefore, warming on the north side of the mountains could only be caused by vertical motions, which are expressed by the third term on the RHS of (2). By integrating the third term on the RHS of (2) from 1300 UTC 08 to 1700 UTC 08 , we identified an average warming of $1.78^{\circ} \mathrm{C}$ over the area $\left(44-44.5^{\circ} \mathrm{N}, 84-87^{\circ} \mathrm{E}\right)$, which indicates the effect of vertical motion. As shown in the vertical sec- tion in Figs. 10e and 10f, when the upper northwest air stream encountered the Tianshan Mountains, it sunk along the north hillside and was accompanied by potential temperature increases. Any vertical motions should be generated by mountainous terrain blockage. This blockage effect on the airflow can be described by the Froude number (Smith 1989):

$$
F_{r}(z)=V(z) /\left(N(z)\left(\overline{h_{\text {terrain }}}-h_{\text {air }}(z)\right)\right),
$$

where $V(z)$ refers to the mean speed of the airflow at the height of $z, N(z)$ is the mean Brunt-Väisälä frequency of the air current, and $\overline{h_{\text {terrain }}}-h_{\text {air }}(z)$ represents the height to which the air current must climb. Under the condition of $F_{r} \leqslant \mathrm{O}(1)$, lower airflow can hardly climb over the mountain ridge. Through calculation, the $F_{r}$ at $750 \mathrm{hPa}$ is 0.2 at 1300 UTC 08 and on the vertical section of Fig. 10e such that the airflow at the lower atmosphere sank at the windward slope.

The sinking airflow motions speeded up the pressure decline near the surface. Therefore, the pressure difference across the canyon increased accordingly, which in turn led to the pressure gradient force. Figure 11 shows the temperature variation over the Urumchi Basin, obtained by AMDAR observations, proving that air warming occurred near the Urumchi Basin from the upper to the ground levels before and during the gale event.

\subsection{Non-linear process}

Simulation results show that $2 \mathrm{~h}$ after the critical layer emerged at 1600 UTC 08 (Fig. 6a), a gale region with a speed over $10 \mathrm{~m} \mathrm{~s}^{-1}$ occurred near the canyon's northwest opening at $850 \mathrm{hPa}$ (Fig. 6c). The windy region then rapidly dominated the exit region and expanded downstream of the canyon (Fig. 7c). Figure 12 shows the distribution of turbulent kinetic energy (TKE) during these hours. High TKE appeared after 1800 UTC 08, which was consistent with the diagnostic results. The turbulence then began to strengthen in the canyon's exit area, indicating that the non-linear effect of topographic gravity waves was active in this area. Scinocca and Peltier (1993) found that the streamline overturn of non-linear gravity waves can include convective instability and turbulent mixing, producing a neutral stratification within the local atmosphere; the turbulent mixing layer will gradually expand downwards, building a large-amplitude perturbation similar to a hydraulic jump on the topographic lee slope. Consequently, the surface wind speed would quicken considerably, generating a downslope windstorm. Clark and Peltier $(1977,1984)$ and Peltier and 

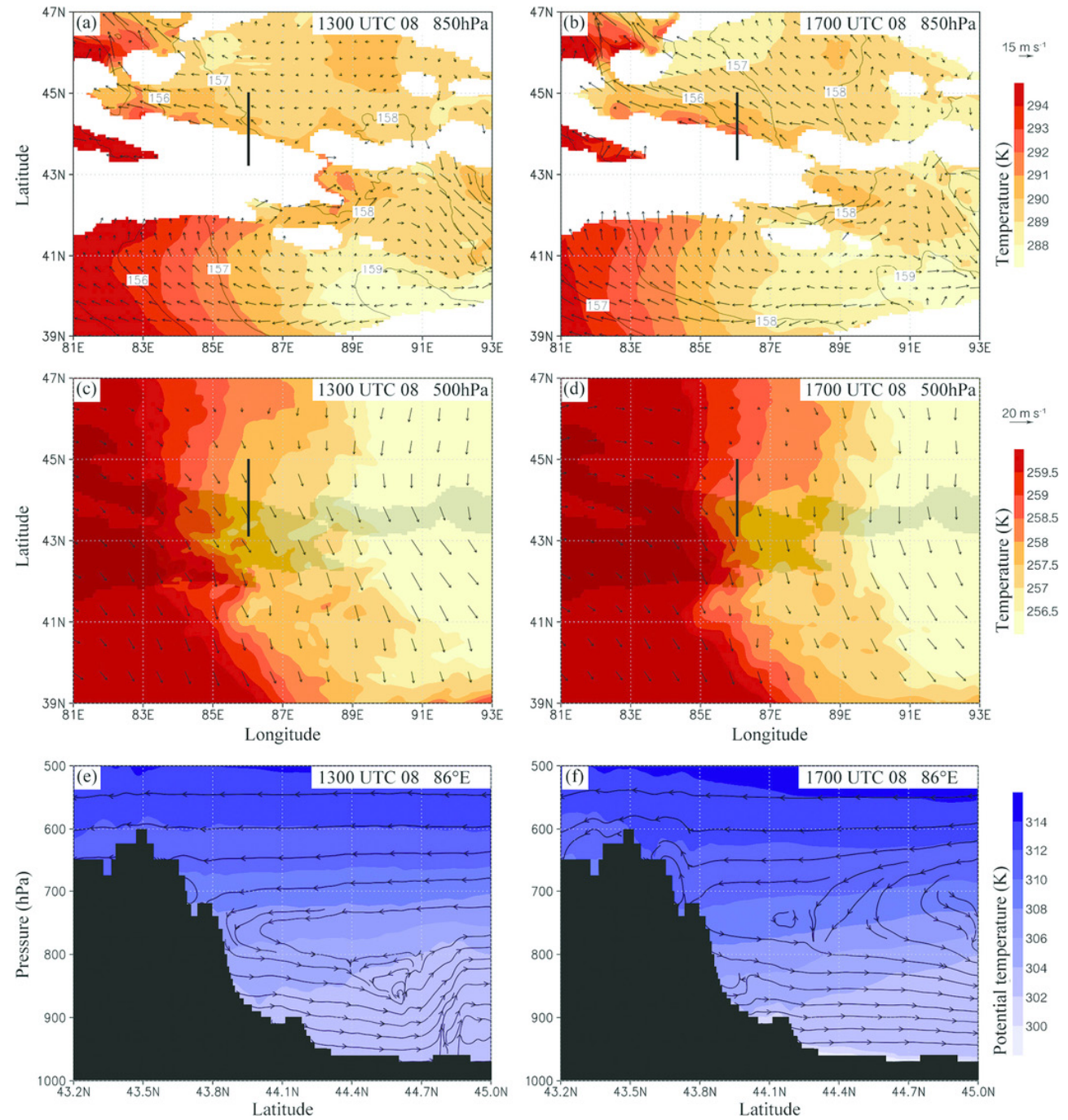

Fig. 10. Distributions of temperature, wind, and geopotential height fields at $850 \mathrm{hPa}$ at (a) 1300 UTC 08 June 2013 and (b) 1700 UTC 08 June 2013. The black isolines indicate the geopotential height at 10 geopotential meter intervals, and the isoline values were obtained by dividing geopotential heights by 10 . Temperature and wind field distributions at $500 \mathrm{hPa}$ at (c) 1300 UTC 08 June 2013 and (d) 1700 UTC 08 June 2013. The black shadow areas are outlines of the Tianshan Mountains. The potential temperature field and flow on the vertical section along $86^{\circ} \mathrm{E}$ on the black lines in (a)-(d) at (e) 1300 UTC 08 June 2013 and (f) 1700 UTC 08 June 2013.

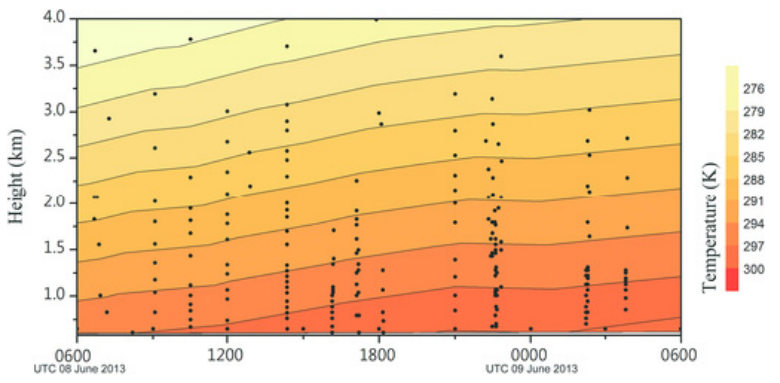

Fig. 11. Variations in temperature above Urumchi based on AMDAR sounding data. The black dots represent the observation sample points. 

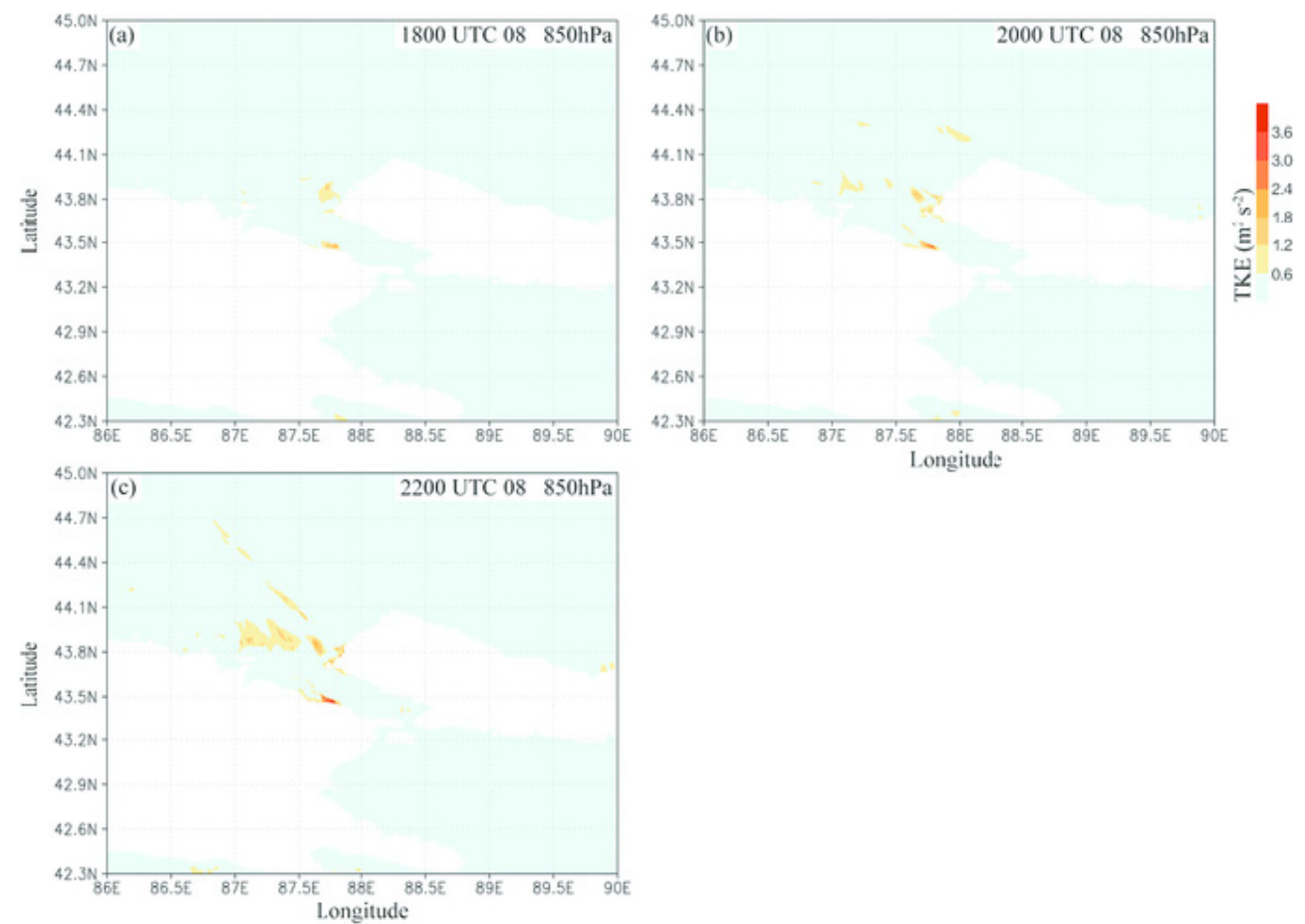

Fig. 12. Distributions of the turbulent kinetic energy field at $850 \mathrm{hPa}$ at (a) 1800 UTC 08 June 2013, (b) 2000 UTC 08 June 2013, and (c) 2200 UTC 08 June 2013.

Clark (1979) explained the gale on the topographic lee slope in terms of a resonance mechanism that, if the critical layer is located at $z_{c}=(3 / 4+n) \lambda$ (where $n$ is an integer and $\lambda=2 \pi /(N / V)$ denotes the vertical wavelength of gravity wave), resonance can occur between the reflected and incident waves, such that the wind velocity near the surface is strengthened. However, Smith (1985) stated that a gale can be generated near the surface as long as the height of the critical layer is between $z_{c}=(1 / 4+n) \lambda$ and $z_{c}=(3 / 4$ $+n) \lambda$. Because the atmosphere in the case study is not a steady flow, the mean vertical wavelength of the gravity waves could be defined as:

$$
\bar{\lambda}=1 /\left(h_{z_{c}}-h_{\text {surface }}\right) \cdot \int_{h_{\text {surface }}}^{h_{z_{c}}} 2 \pi /(N(z) / V(z)) d z
$$

Based on the calculation at 1600 UTC 08 , the mean wavelength $\bar{\lambda}$ is $4676 \mathrm{~m}$ above the canyon, the height of $z_{c}=3 / 4 \cdot \bar{\lambda}$ is $3507 \mathrm{~m}(671 \mathrm{hPa})$, and the height of $z_{c}=1 / 4 \cdot \bar{\lambda}$ is $1169 \mathrm{~m}(887 \mathrm{hPa})$. In addition, the simulation results shown in Fig. $6 \mathrm{a}$ indicate that the critical layer height was approximately $750 \mathrm{hPa}$ above the canyon at 1600 UTC 08 , so it was between $1 / 4 \cdot \bar{\lambda}$ and $3 / 4 \cdot \bar{\lambda}$. Establishment of the critical layer could indicate potentially unstable stratification in the local atmosphere. In addition, the vertical motions appeared as a result of non-linear gravity wave activities and then accelerated the wind speed near the surface at the lee slope of the canyon.

\section{Conclusion}

To describe the southeasterly gale at Urumchi, Xinjiang, China that occurred on 8 June 2013, we conducted a numerical simulation by employing the WRF model to reconstruct the gale's synoptic background and characteristics.

The gale's occurrence was directly related to the high and low pressure field situations in the southeast and northwest parts of the Tianshan Grand Canyon, respectively. These pressure field situations occurred in a large-scale synoptic condition in which the thermal ridge moved eastward over the Tianshan Mountains. The northerly air current in front of the thermal ridge sank on the north foot of the Tianshan Mountains because it was blocked by the terrain, heating the lowlevel atmosphere. Consequently, the regional pressure decline on the northern foot of the mountains formed 
a pressure gradient force across the Tianshan Grand Canyon (Fig. 10). Subsequently, the air current began to travel across the canyon, and a critical layer emerged near $750 \mathrm{hPa}$ above the canyon (Fig. 6). A non-linear process was then activated and formed a downslope windstorm on the canyon's lee slope (Fig. 7).

Through diagnostic analysis, we determined the greatest contributor to this gale's generation was a low-level pressure gradient force across the canyon. The non-linear motion of gravity waves also provided considerable momentum downward, toward the exit area of the canyon, which was another important contributor to the gale.

Although this study derived characteristics of the southeasterly gale from observations and a numerical simulation, certain concerns that are worth closer inspection remain. Most importantly, the question remains as to what caused this gale to be the strongest in the past 20 years. It may have been related to the strength and location of the warm ridge. Only when the warm ridge extends to the north of the Tianshan Mountains does low-level pressure decline on the northern foot of the mountains. This assumption should be verified through other studies of southeasterly gales. Second, the wind observations, as described in this study, were only surface observations; the actual structure of these weather phenomena requires high-frequency sounding observations. In addition, in the winter, southeasterly gales do not normally contact the ground. Is this related to the inversion layer near the surface and will it generate atmospheric ducting? These are additional questions to be addressed, through further exploration, to improve our ability to forecast these types of weather incidents.

\section{Acknowledgments}

We thank the Civil Aviation Air Traffic Control Bureau of Xinjiang Meteorological Center for offering the observational data. We also thank Jianfeng $\mathrm{Gu}$ and Hong Huang for their many suggestions and the reviewers for their comments on the manuscript. This research work is supported by Jiangsu Provincial Natural Science Foundation of China [BK20170751] and National Natural Science Foundation of China [41775039].

\section{References}

Booker, J. R., and F. P. Bretherton, 1967: The critical layer for internal gravity waves in a shear flow. J. Fluid. Mech., 27, 513-539.

Clark, T. L., and W. R. Peltier, 1977: On the evolution and stability of finite-amplitude mountain waves. $J$.
Atmos. Sci., 34, 1715-1730.

Clark, T. L., and W. R. Peltier, 1984: Critical level reflection and the resonant growth of nonlinear mountain waves. J. Atmos. Sci., 41, 3122-3134.

Colle, B. A., and C. F. Mass, 1998: Windstorms along the western side of the Washington Cascade Mountains. Part I: A high-resolution observational and modeling study of the 12 February 1995 event. Mon. Wea. Rev., 126, 28-52.

Colman, B. R., and C. F. Dierking, 1992: The Taku wind of southeast Alaska: Its identification and prediction. Wea. Forecasting, 7, 49-64.

Dudhia, J., 1989: Numerical study of convection observed during the Winter Monsoon Experiment using a mesoscale two-dimensional model. J. Atmos. Sci., 46, 3077-3107.

Durran, D. R., 1986: Another look at downslope windstorms. Part I: The development of analogs to supercritical flow in an infinitely deep, continuously stratified fluid. J. Atmos. Sci., 43, 2527-2543.

Fudeyasu, H., T. Kuwagata, Y. Ohashi, S. Suzuki, Y. Kiyohara, and Y. Hozumi, 2008: Numerical study of the local downslope wind "Hirodo-Kaze" in Japan. Mon. Wea. Rev., 136, 27-40.

Gaberšek, S., and D. R. Durran, 2004: Gap flows through idealized topography. Part I: Forcing by large-scale winds in the nonrotating limit. J. Atmos. Sci., 61, 2846-2862.

Janjić, Z. I., 1994: The step-mountain eta coordinate model: Further developments of the convection, viscous sublayer, and turbulence closure schemes. Mon. Wea. Rev., 122, 927-945.

Klemp, J. B., and D. R. Lilly, 1975: The dynamics of waveinduced downslope winds. J. Atmos. Sci., 32, 320339.

Mlawer, E. J., S. J. Taubman, P. D. Brown, M. J. Iacono, and S. A. Clough, 1997: Radiative transfer for inhomogeneous atmosphere: RRTM, a validated correlated-k model for the longwave. J. Geophys. Res., 102, 16663-16682.

National Centers for Environmental Prediction/National Weather Service/NOAA/U.S. Department of Commerce, 2000: NCEP FNL Operational Model Global Tropospheric Analyses, continuing from July 1999. Research Data Archive at the National Center for Atmospheric Research, Computational and Information Systems Laboratory. [Available at https://doi. org/10.5065/D6M043C6.]

National Centers for Environmental Prediction/National Weather Service/NOAA/U.S. Department of Commerce, European Centre for Medium-Range Weather Forecasts, and Unidata/University Corporation for Atmospheric Research, 2003: Historical Unidata Internet Data Distribution (IDD) Gridded Model Data. Research Data Archive at the National Center for Atmospheric Research, Computational and Information 
Systems Laboratory. [Available at http://rda.ucar.edu/ datasets/ds335.0/.]

Overland, J. E., and B. A. Walter, Jr., 1981: Gap winds in the Strait of Juan de Fuca. Mon. Wea. Rev., 109, 22212233.

Paulson, C. A., 1970: The mathematical representation of wind speed and temperature profiles in the unstable atmospheric surface layer. J. Appl. Meteor, 9, 857861.

Peltier, W. R., and T. L. Clark, 1979: The evolution and stability of finite-amplitude mountain waves. Part II: Surface wave drag and severe downslope windstorms. J. Atmos. Sci., 36, 1498-1529.

Smith, R. B., 1985: On severe downslope winds. J. Atmos. Sci., 42, 2597-2603.

Smith, R. B., 1989: Hydrostatic airflow over mountains. Adv. Geophys., 31, 1-41.

Scinocca, J. F., and W. R. Peltier, 1993: The instability of Long's stationary solution and the evolution toward severe downslope windstorm flow. Part I: Nested grid numerical simulations. J. Atmos. Sci., 50, 2245-2263.

Skamarock, W. C., J. B. Klemp, J. Dudhia, D. O. Gill, D. M. Barker, M. G. Duda, X. Y. Huang, W. Wang, and J. G. Powers, 2008: A description of the advanced research WRF version 3. NCAR Tech. Note NCAR/TN-475+ STR, 125 pp.

Tewari, M., F. Chen, W. Wang, J. Dudhia, M. A. LeMone, K. Mitchell, M. Ek, G. Gayno, J. Weigel, and R. H. Cuenca, 2004: Implementation and verification of the unified Noah land surface model in the WRF model. 20th Conf. on Weather Analysis and Forecasting/16th Conf. on Numerical Weather Prediction. Amer. Meteor. Soc., 14 January, 2004, Washington, 14.2A. [Available at https://ams.confex.com/ams/pdfpapers/ 69061.pdf.]

Zängl, G., 2002: Stratified flow over a mountain with a gap: Linear theory and numerical simulations. Quart. J. Roy. Meteor. Soc., 128, 927-949. 